\title{
Integration Function of HRM - A Case Study
}

\author{
Dr K P Radhika ${ }^{1}$ \\ $\left\{\right.$ kpr.hm@psgtech.ac.in $\left.{ }^{1}\right\}$
}

Assistant Professor, Department of Humanities, PSG College of Technology, Coimbatore

\begin{abstract}
This study gives us an notion about the integration function of human resource management without which the concept of engaging the employees in the organization to make them to work with bonding becomes a question mark. The concept of integration function generates the plan to reconsider organization goals to manage the employees within the organization in a effective way so that the employee's loyalty and performance will increase to a greater extent. In this case we can identify the possibility of attrition is due to improper integration of employees and no new changes have been adopted to make the employees to hold citizenship towards the organization.
\end{abstract}

Keywords: Integration, HR strategy, BPO, Attrition.

\section{Introduction to Integration Function}

The human resource field considers "integration function" as imperative for associations to incorporate the "objectives of the association" with "employee yearnings" through different employee-arranged projects like complaint redressal, discipline, group the board, aggregate dealing, engaging employees and modern relations. (Rao, 2000) The steadily changing and serious work styles, dynamic basis, detailing connections, association structure, and working models have all affected employees' presentation.

Dealing with the bunch of HR jobs and prerequisites during integration requests a successful HR integration plan that lines up with the general integration methodology. With a devoted HR pioneer and integration group executing the arrangement, the recently joined organization ought to get the adaptability they need to draw in ability and drive development. (ShunguChigariro and Gregg Nahass, 2017).

Organizations with less distinct HR integration function have encountered a more prominent probability of business interference, ability deserting, declining deals, and market disarray over the course of the organization .

\section{Review of Literature}

Without effective labor force associations lose their capacity to contend, both locally and globally, in the long run prompting poor authoritative execution and accordingly winding up with almost no financial achievement (Jing et al, 2005).

Ongoing explores on human resource management (HRM) show a solid and positive connection between its practices and hierarchical execution (Anderson et al, 2004). 
Human resource management exercises would become key in case the organization's way of thinking, arrangements, programs, rehearses, human resource management measures, and key necessities were methodically connected (Budhwar, 2000).

Realizing the significance of the "Integration role of HR" in today's competitive MNCs, the present case study is an attempt to highlight the "integration" role of HR in a medium-sized developing IT organization. The organization is selected owing to the significant role of employees in productivity owing to be in the BPO industry. The case study is structured as follows: a) overview of the company b) case scenario d) suggestions and e) conclusion.

a) Soft Tech Inc. - an overview

Soft Tech Inc. has been developing and deploying high-value, productivityenhancing technology solutions for medium-sized and enterprise-level organizations. Founded in 1994 in Cranbury, New Jersey, Soft Tech offers its clients a comprehensive range of technology-related services, including business consulting, software products, administration, helpdesk, content migration, database management, and other technology services, and technology-driven business process outsourcing. Soft Tech was into both IT development and BPO havingoffshore centers utilizing state of the art technologies and industry best practices to deliver its solutions.

\section{Organization Structure of Soft Tech:}

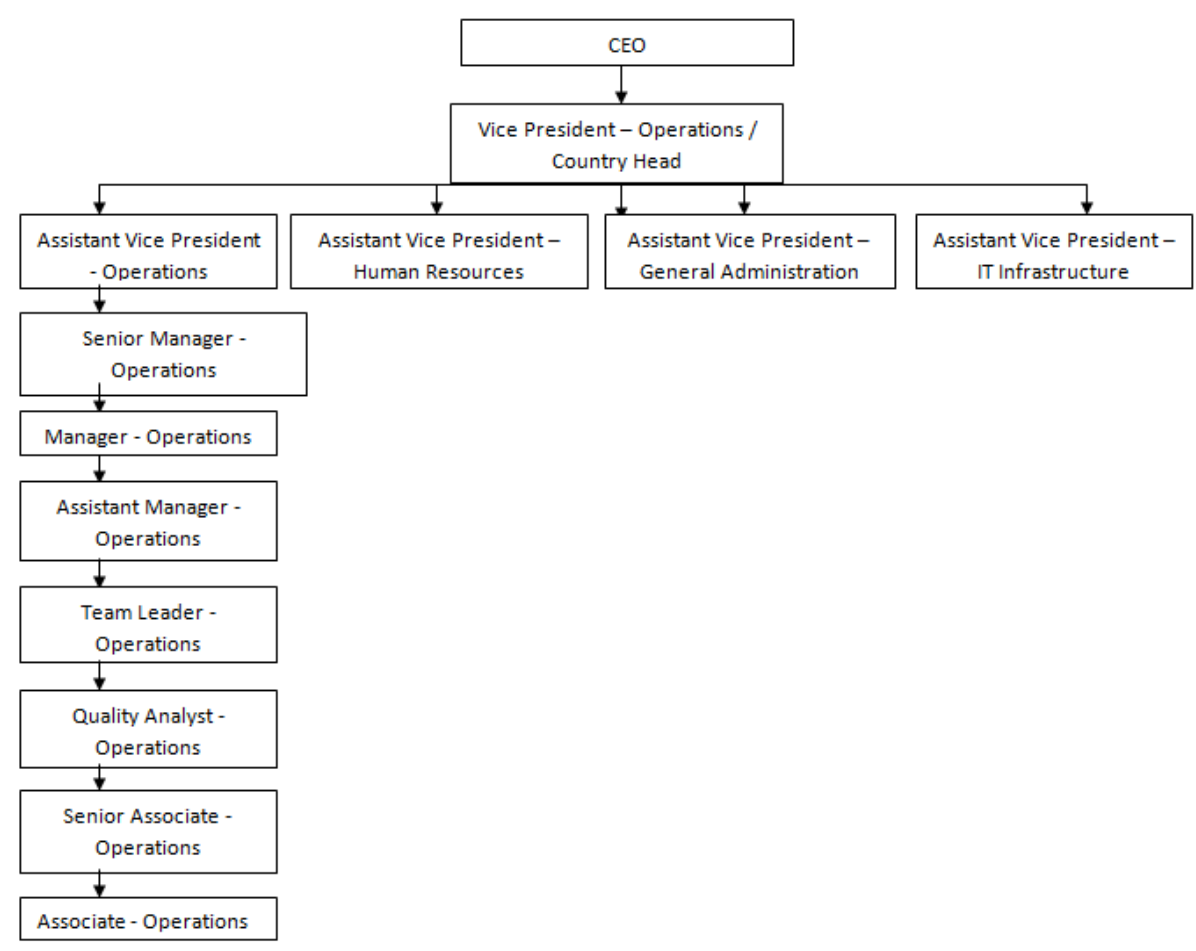




\section{Case Scenario - issues and challenges}

The incorporation of Soft Tech BPO in India was viewed successfully with the appointment of Mr.Sujith as Vice President (Operations) and Country Head, who had an experience of 20 years of experience in the Business Process Outsourcing (BPO) domain with proven efficiency. There was a positive vibe in the organization among the employees about the working styles and leadership of Sujith, who was known for encouraging individual autonomy among the employees.

Sujith decided against appointing Assistant Vice President (Operations) to empower his employees' talent and also to strengthen the team. In the process, Mr. Jithin, who had an experience of 12 years and proven talent was selected for the role. Mr. Jithin was assigned tasks of strengthening the teams' performance, dispute handling, client management, and policy framing. Jithin's appointment was seen as a feather to the cap of the team, with his dynamism and leadership style. Sujith was now able to concentrate more effectively and personally on client relationships for building the business.

In his course of developing strong relationships with clients, Sujith developed ideas for his business venture. This news reached the ears of the top management and spread widely across the company. The management viewed this opinion of Sujith as an act of disloyalty and terminated Sujith immediately. The employees of the organization, by and large, were shocked by this decision of the management and reacted in different ways. They feared the loss of individual autonomy that Sujith had guaranteed them throughout his tenure, which made employees more empowered and motivated. This scenario created a slip in the organizational efficiency in the short run.

\section{Solutions identified}

$\checkmark$ According to this case study, Harry shouldn't have fired Sujith immediately. He should have spoken to him to know what his intention is and should have been given a chance to justify the downtrend in business. Moreover, Harry should have taken the responsibility to make Sujith understand about the current situation and should have made him drop the idea of starting a new business on his own to avoid competitors and an offer could have been given in such a way to make Sujith understand that the offer provided is better than starting a new business.

$\checkmark$ Possibly the style of work may get affected because Sujith was having a better understanding of employees. As he has left, the employees may get demotivated. And the client relationship will get affected as Sujith was taking care of it all alone. The concept of "work avoidance" may prevail as the employees have lost a leader who was very much close to them.

$\checkmark \quad$ The challenges that Jithin will start facing are creating a good rapport with the client, strategies should be framed to retain the existing business as there are possibilities for Sujith to take the clients with him as he is starting a new firm, there is also a chance that Sujith can deliberately create issues inside Soft Tech by providing better opportunities for the employees and also better salary package which has to be taken care by Jithin. 


\section{Questions}

1. Was the decision of firing Sujith without inquiry right or wrong? Justify.

2.What will be the possible reactions and impact of Sujith's termination inside Soft Tech?

3. Identify the integration roles for the HR leader of Soft Tech.

\section{References}

[1] Anderson, N., Lievens, F., van Dam, K., \& Ryan, A.M. (2004). Future perspectives on employee selection, Key directions for future research and practice. Applied Psychology, An International Review, 53(2), 487-501.

[2] Budhwar, P. (2000). Strategic integration and development of human resource management in UK manufacturing. British Journal of Management, 11(1), 285-302.

[3] "Human Resource Management - Text and Cases" VSP Rao 2000.

[4] ShunguChigariro and Gregg Nahass, 2017, PwC 2017 M\&A Integration survey report pp 1-11.

[5] SJing, W. Huang, T. (2005) Relationship between Strategic Human Resources Management and Firm Performance, International Journal of Manpower, pp. 434-449. 